\title{
Investigation of a flow step clogging incident: A precautionary note on the use of THF in commercial-scale continuous process.
}

\author{
Nelo R. Rivera*a, Brittany Kassim*a, Plamen Grigorov ${ }^{\mathrm{c}}$, Heather Wang ${ }^{\mathrm{b}}$, Marco Armenantec, \\ Xiaodong $\mathrm{Bu}^{\mathrm{a}}$, Azzeddine Lekhal ${ }^{\mathrm{c}}$, Narayan Variankaval ${ }^{\mathrm{a}}$ \\ ${ }^{a}$ Small Molecules Analytical Research and Development; ${ }^{b}$ Enabling Technologies Analytical \\ Research and Development; ' Chemical Engineering Research and Development. Merck \& Co., \\ Inc., P.O. Box 2000, Rahway, NJ 07065, USA \\ *Corresponding authors,e-mail address: nelo_rivera@merck.com; brittany.kassim@merck.com
}

\section{Supplementary Information}

I. MALDI mass spectra of isolated poly(THF)

page 2

II. NMR spectra of isolated poly(THF)

page 3-5 


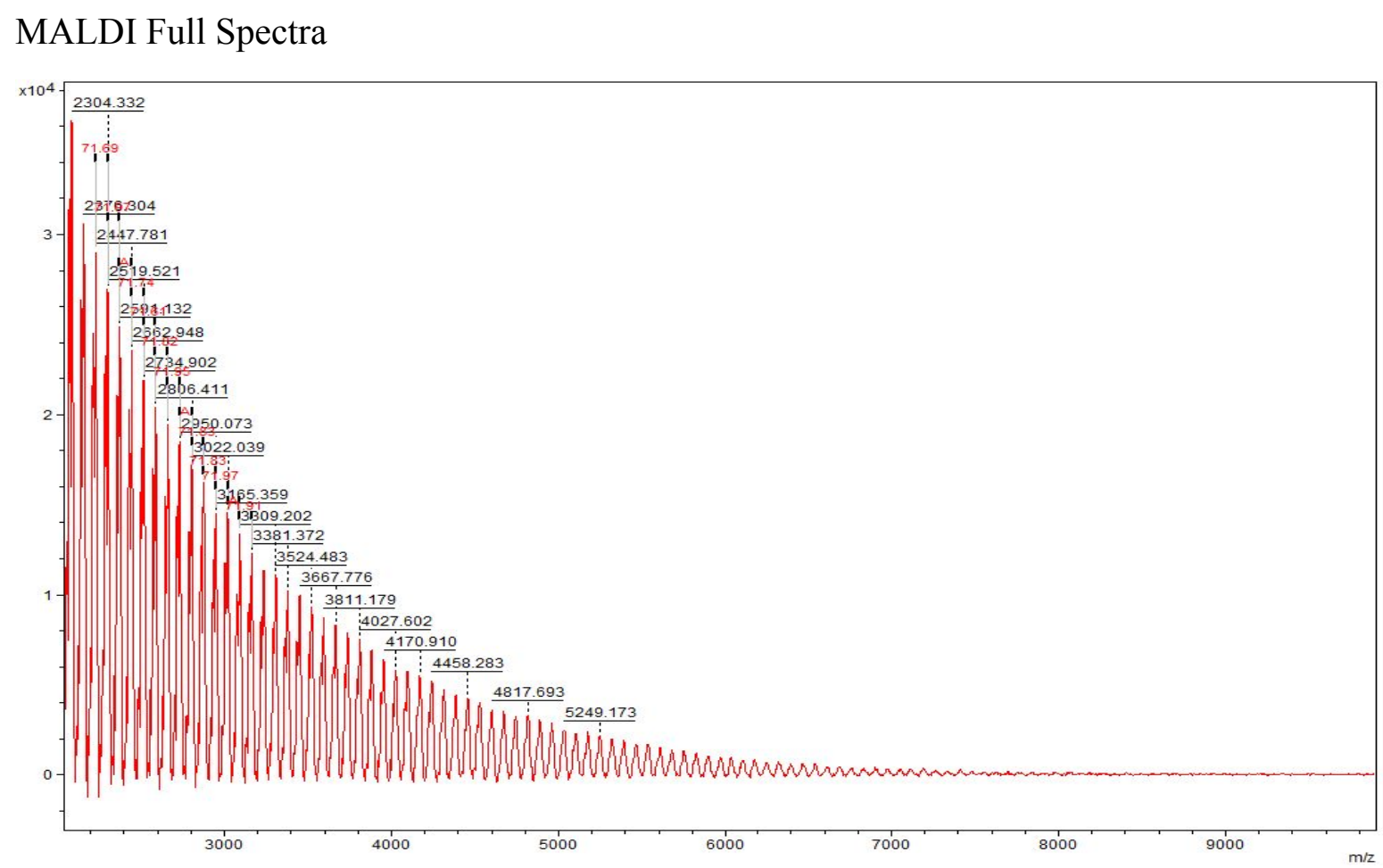

\section{MALDI Expanded Spectra}

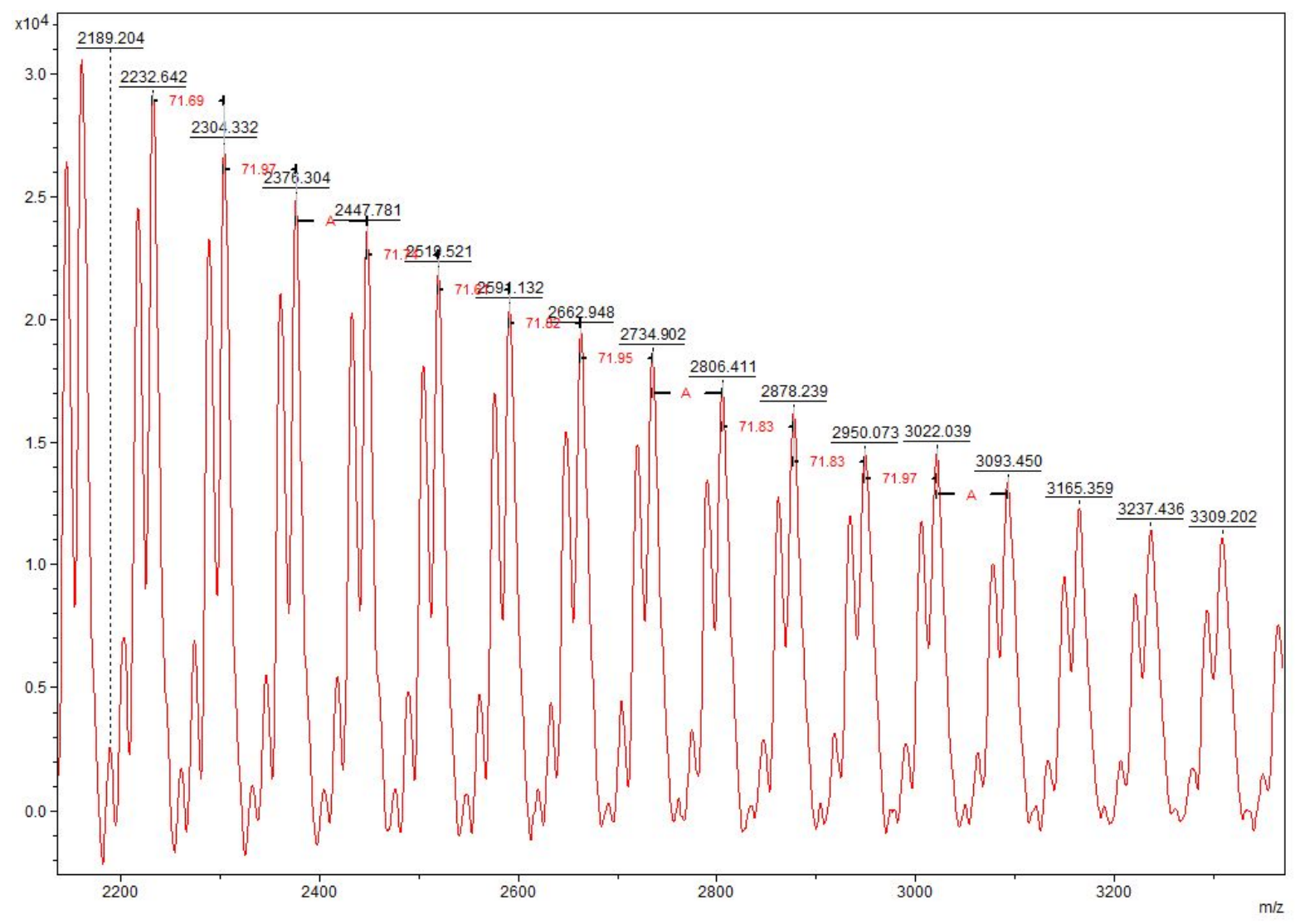



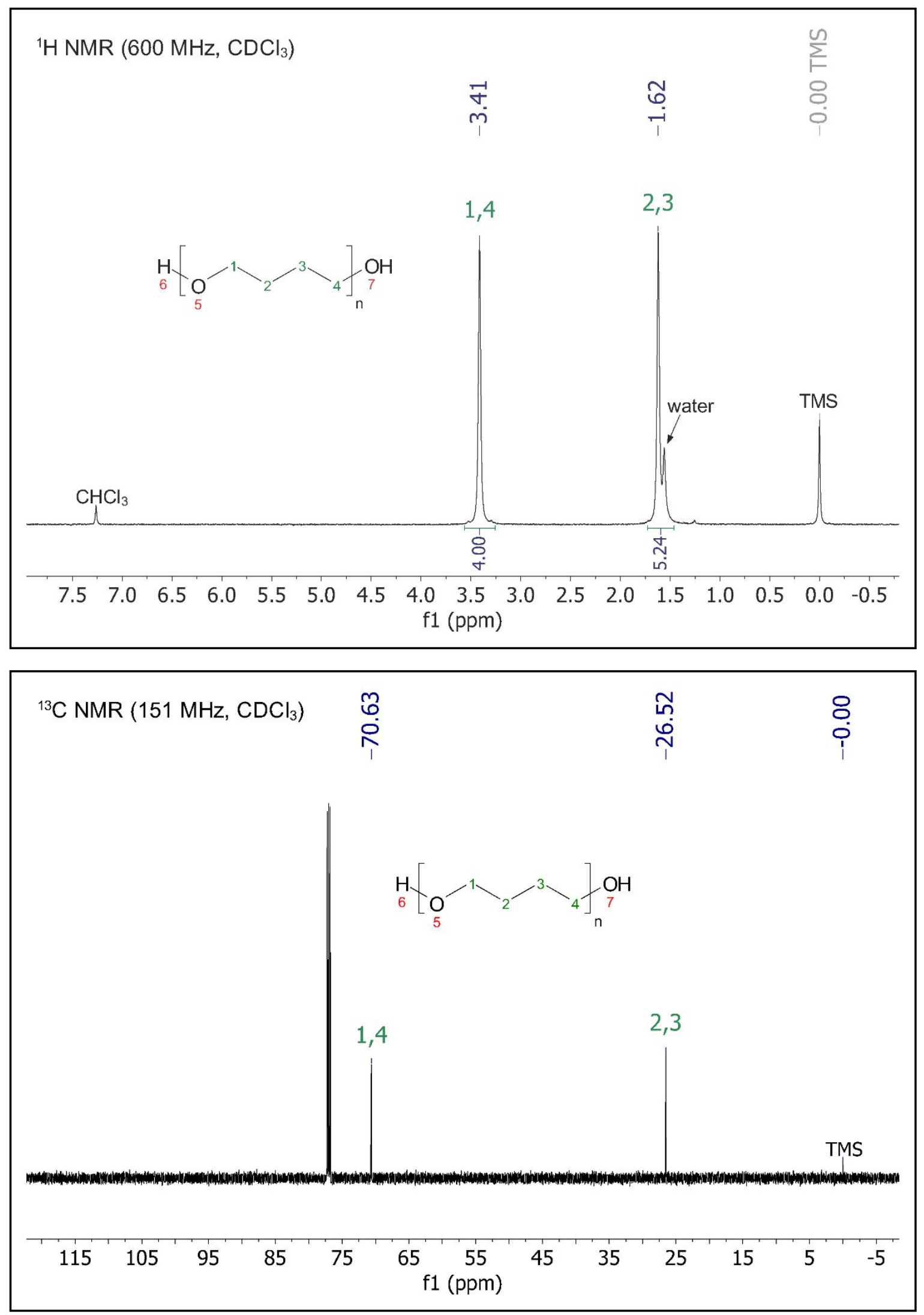


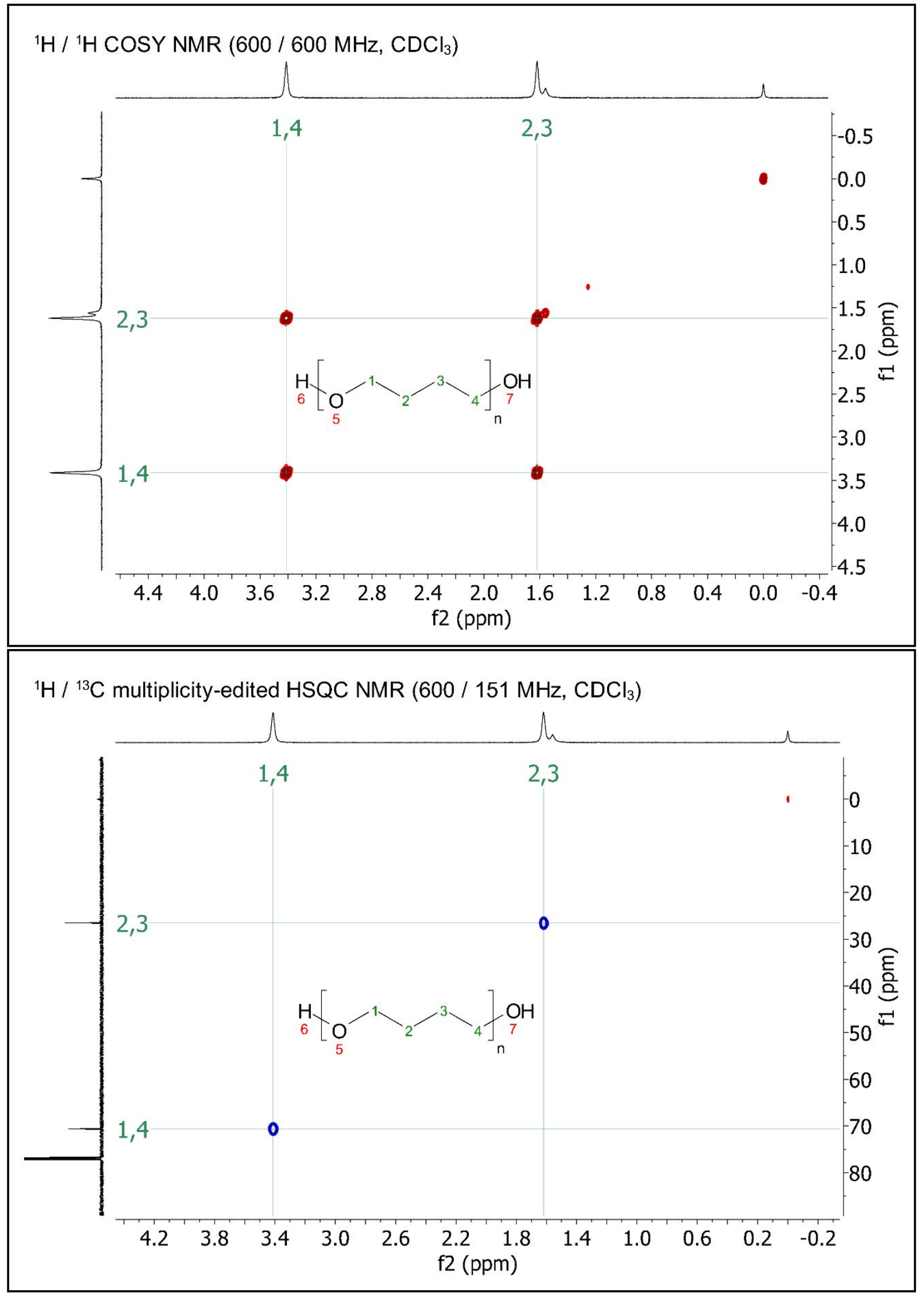




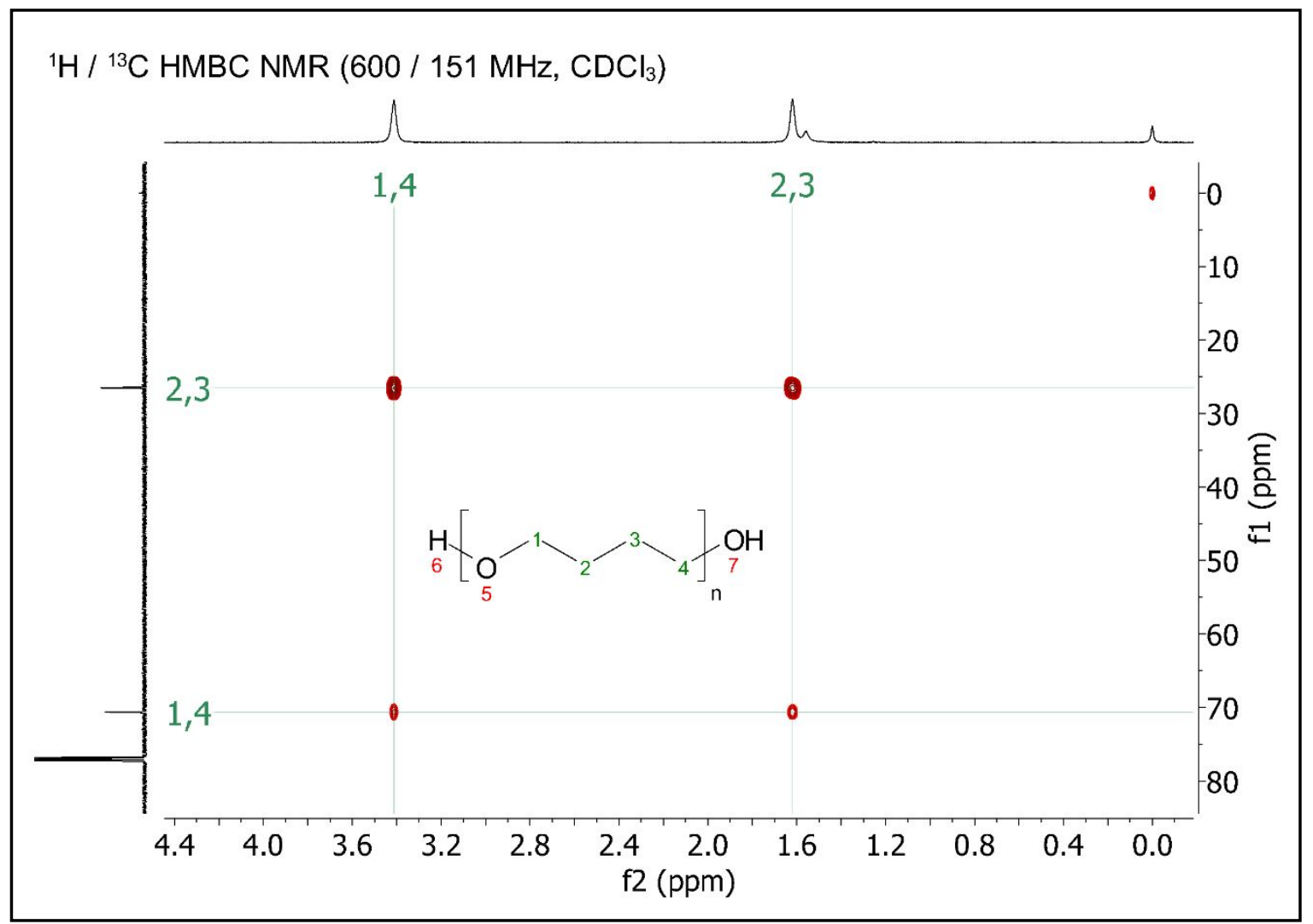

